\section{Neu und Alt im INTERNETT}

DMV-Jahrestagung Dresden http://www . math.tu-dresden.de/DMV2000/

WEBIS - Sammelschwerpunkte an deutschen Bibliotheken http://webis.sub.uni-hamburg.de

Althöfers Ex-Studenten und ihre Berufe

(vgl. Mitteilungen 4-99)

http://www.minet.uni-jena.de/www/fakultaet/ iam/personen/exstudenten.html

Science's Next Wave - für Nachwuchswissenschaftler http://www. nextwave.org/de

WMY2000

http: //wmy2000.math.jussieu.fr

„Der Kaiserslauterner Mathematik-Kalender" http://www.itwm. uni-kl.de/ebene1/aktuelles. html

\section{Ergebnis der Präsidiumswahlen}

\section{Wahl des weiteren Präsidiums}

Abgegebene Stimmzettel
Gültige Stimmzettel
Stimmen für Herrn Joachim Cuntz
Stimmen für Frau Claudia Klüppelberg
Stimmen für Herrn Rudolf Scharlau
Stimmen für Herrn Jochem Zowe

435 Stimmen 522 Stimmen 477 Stimmen 331 Stimmen

Damit sind Frau Klüppelberg und Herr Scharlau als neue Präsidiumsmitglieder gewählt.

Herr Cuntz und Herr Zowe sind als Nachrücker gewählt.

Der gemäß der Wahlordnung eingesetzte Wahlausschuss besteht aus den Mitgliedern: Erhard Behrends (Wahlleiter), Klaus Fleischmann, Elmar Vogt.

Die Auszählung der Stimmen erfolgte am 6. 12. 1999. gez. Erhard Behrends Klaus Fleischmann Elmar Vogt

\section{Ein Hauch Y2K}
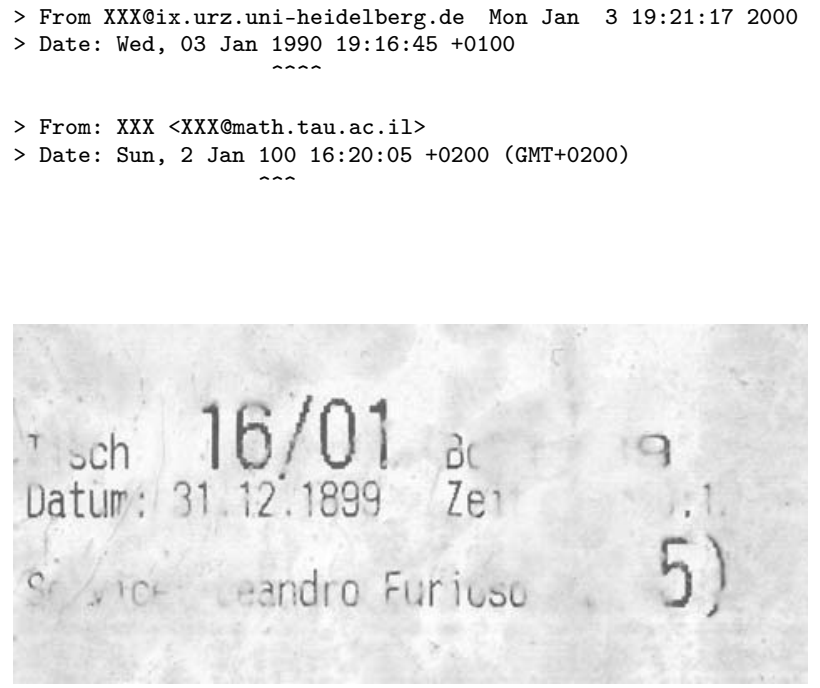

\section{Wahre Begebenheit}

Erste reguläre Vorlesung im neuen Semester: Höhere Mathematik I für Elektrotechniker. Ich bin ein paar Minuten vor Beginn im Hörsaal und setze mich in die erste Reihe. Da spricht mich ein Student an, mit asiatischem Gesichtsschnitt und asiatischer Höflichkeit.

„Herr Professor, ich habe bei Ihrer Einführung mitgeschrieben."

Das Kollegheft wird präsentiert.

„Sie haben da geschrieben $i^{2}=-1$. Das ist doch ein Versehen?"

„Nein, nein, das ist kein Versehen ..."

„Aber es ist doch ein Quadrat."

„Ja, es ist ein Quadrat und dennoch negativ ..."

„Aber das ist ein Wunder!“

(Dirk Ferus, TU Berlin) 